\title{
Measuring Customer Satisfaction for Various Services Using Multicriteria Analysis
}

\author{
Yannis Siskos and Evangelos Grigoroudis \\ Technical University of Crete \\ Decision Support Systems Laboratory \\ University Campus, 73100 Chania, GREECE
}

Key words: Customer satisfaction, Preference disaggregation, Ordinal regression, and Multicriteria analysis

Abstract: Quality evaluation and customer satisfaction measurement is a necessary condition for applying continuous improvement and total quality management philosophies. This justifies the need for developing modern operational research and management tools, which will be sufficient enough to analyse in detail customer satisfaction. The original applications presented through this paper implement the MUSA method, a preference disaggregation model following the principles of ordinal regression analysis. These applications concern customer satisfaction surveys from the public and the private sector as well, and they are selected in such a way so that can indicate the contribution of multicriteria analysis to the quality evaluation problem. Furthermore, the presented analyses demonstrate in practice the implementation process of satisfaction measurement projects in different types of business organisations.

\section{INTRODUCTION}

Customer satisfaction is one of the most important issues concerning business organisations of all types, which is justified by the customerorientation philosophy and the main principles of continuous improvement of modern enterprises. For this reason, customer satisfaction should be measured and translated into a number of measurable parameters. Customer satisfaction measurement may be considered as the most reliable feedback, 
considering that it provides in an effective, direct, meaningful and objective way the clients' preferences and expectations. In this way, customer satisfaction is a baseline standard of performance and a possible standard of excellence for any business organisation (Gerson, 1993).

The aim of this paper is to present original customer satisfaction evaluation projects in different business organisations from the public and the private sector. The objectives of the customer satisfaction surveys are focused on the assessment of the critical satisfaction dimensions, by means of qualitative questions, and the determination of customer groups with distinctive preferences and expectations.

The methodological approach is based on the principles of multicriteria modelling, while the preference disaggregation MUSA (MUlticriteria Satisfaction Analysis) method is used for data analysis and interpretation.

The paper consists of six sections. Section 2 is devoted to the contribution of multicriteria analysis to the customer satisfaction evaluation problem, while an analytical presentation of the MUSA method is discussed in section 3. The next two sections present five original customer satisfaction surveys in public services (post office, university department) and the private sector (mobile phone service provider, airline company, and fast food company). Finally, section 6 presents some concluding remarks, as well as future research in the context of the proposed methodological approach.

\section{CUSTOMER SATISFACTION AND MULTICRITERIA ANALYSIS}

Although, extensive research has defined several alternative approaches for the customer satisfaction evaluation problem, all these proposed models and techniques, so far, adopt the following main principles (Grigoroudis, 1999):

a) The data of the problem are based on the customers' judgements and should be directly collected from them.

b) Customer satisfaction measurement is a multivariate evaluation problem given that customer's global satisfaction depends on a set of variables representing service characteristic dimensions.

c) Usually, an additive formula is used in order to aggregate partial evaluations in a global satisfaction measure.

Based on these assumptions the customer satisfaction evaluation problem can be formulated in the context of multicriteria analysis, assuming that client's global satisfaction depends on a set of criteria or variables representing service characteristic dimensions (Figure 1). 


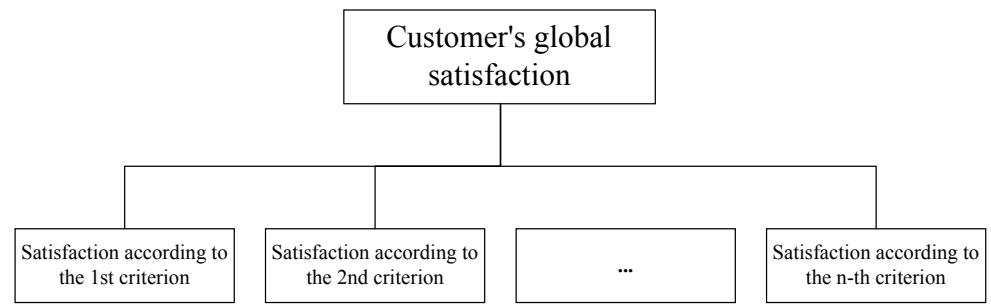

Figure 1. Aggregation of customer's judgements

The preference disaggregation MUSA method is an ordinal regression based approach (Jacquet-Lagrèze and Siskos, 1982; Siskos, 1985; Siskos and Yannacopoulos, 1985) in the field of multicriteria analysis. The method is used for the assessment of a set of marginal satisfaction functions in such a way that the global satisfaction criterion becomes as consistent as possible with customer's judgements. Thus, the main objective of the MUSA method is the aggregation of individual judgements into a collective value function.

The MUSA method assesses global and partial satisfaction functions $Y^{*}$ and $X_{i}^{*}$ respectively, given customers' judgements $Y$ and $X_{i}$ (for the i-th criterion). The ordinal regression analysis equation has the following form:

$$
\left\{\begin{array}{l}
Y^{*}=\sum_{i=1}^{n} b_{i} X_{i}^{*} \\
\sum_{i=1}^{n} b_{i}=1
\end{array}\right.
$$

where the value functions $Y^{*}$ and $X_{i}^{*}$ are normalised in the interval $[0,100]$, $n$ is the number of criteria, and $b_{i}$ is a positive weight of the i-th criterion.

In several cases, as presented in Sections $4-5$, it is useful to assume a value or treelike structure of criteria, also mentioned as "value tree" or "value hierarchy" (Keeney and Raiffa, 1976; Keeney, 1996; Kirkwood, 1997).

\section{THE MUSA METHOD}

\subsection{Basic inference procedure}

The MUSA method proposed by Grigoroudis and Siskos (2001) infers an additive collective value function $Y^{*}$ and a set of partial satisfaction 
functions $X_{i}^{*}$. The main objective of the method is to achieve the maximum consistency between the value function $Y^{*}$ and the customers' judgements $Y$. Based on the modelling approach presented in the previous section and introducing a double-error variable (see Figure 2), the ordinal regression equation becomes as follows:

$$
\widetilde{Y}^{*}=\sum_{i=1}^{n} b_{i} X_{i}^{*}-\sigma^{+}+\sigma^{-}
$$

where $\widetilde{Y}^{*}$ is the estimation of the global value function $Y^{*}$, and $\sigma^{+}$and $\sigma^{-}$ are the overestimation and the underestimation errors, respectively.

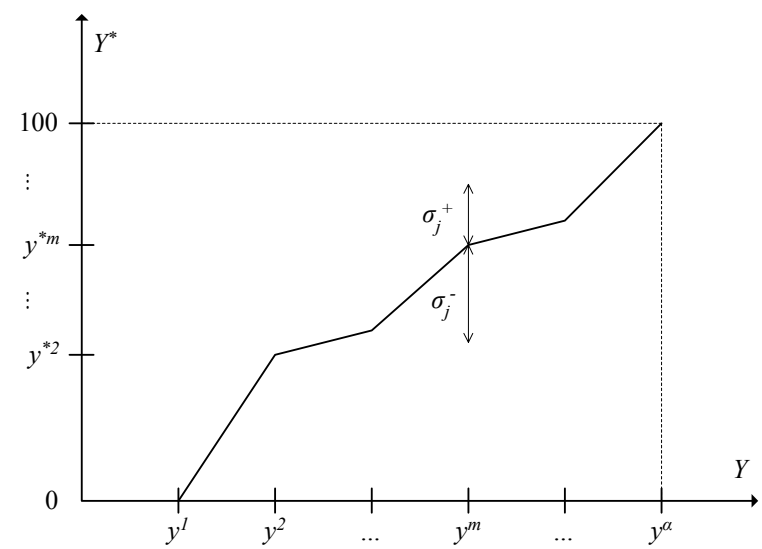

Figure 2. Error variables for the $\mathrm{j}$-th customer

In order to reduce the size of the mathematical program, removing the monotonicity constraints for $Y^{*}$ and $X_{i}^{*}$, the following transformation equations are used:

$$
\begin{cases}z_{m}=y^{*_{m+1}}-y^{*_{m}} & \text { for } m=1,2, \ldots, \alpha-1 \\ w_{i k}=b_{i} x_{i}^{* k+1}-b_{i} x_{i}^{* k} & \text { for } k=1,2, \ldots, \alpha_{i}-1 \text { and } i=1,2, \ldots, n\end{cases}
$$

According to the aforementioned definitions and assumptions, the basic estimation model can be written in a linear program formulation, as follows: 
Multicriteria Analysis

$$
\left\{\begin{array}{l}
{[\min ] F=\sum_{j=1}^{M} \sigma_{j}^{+}+\sigma_{j}^{-}} \\
\text {subject to } \\
\sum_{i=1}^{n} \sum_{k=1}^{t_{i i}-1} w_{i k}-\sum_{m=1}^{t_{j}-1} z_{m}-\sigma_{j}^{+}+\sigma_{j}^{-}=0 \quad \text { for } j=1,2, \ldots, M \\
\sum_{m=1}^{\alpha-1} z_{m}=100 \\
\sum_{i=1}^{n} \sum_{k=1}^{a_{i}-1} w_{i k}=100 \\
z_{m} \geq 0, w_{i k} \geq 0 \quad \forall m, i, k \\
\sigma_{j}^{+} \geq 0, \sigma_{j}^{-} \geq 0 \quad \text { for } j=1,2, \ldots, M
\end{array}\right.
$$

where $M$ is the size of the customers sample, $n$ is the number of criteria, and $x_{i}^{j}, y^{j}$ are the j-th level on which variables $X_{i}$ and $Y$ are estimated.

The preference disaggregation methodology includes also a post optimality analysis stage in order to overcome the problem of model stability. The final solution is obtained by exploring the polyhedron of multiple or near optimal solutions, which is generated by the constraints of the previous linear program. This solution is calculated by $n$ linear programs (equal to the number of criteria) of the following form:

$$
\left\{\begin{array}{l}
{[\max ] F^{\prime}=\sum_{k=1}^{a_{i}-1} w_{i k} \quad \text { for } i=1,2, \ldots, n} \\
\text { under the constraints } \\
F \leq F^{*}+\varepsilon \\
\text { all the constraints of LP (4) }
\end{array}\right.
$$

where $\varepsilon$ is a small percentage of $F^{*}$.

The average of the solutions given by the $n$ LPs (5) may be taken as the final solution. In case of non-stability, this average solution is less representative, due to the large variation among the solutions of LPs (5). A more detailed discussion about post optimality analysis in ordinal regression modelling is given in Jacquet-Lagrèze and Siskos (1982). 


\subsection{Satisfaction indices}

The assessment of a performance norm may be very useful in customer satisfaction analysis. The average global and partial satisfaction indices are used for this purpose and are assessed through the following equations:

$$
\left\{\begin{array}{l}
S=\frac{1}{100} \sum_{m=1}^{\alpha} p^{m} y^{*_{m}} \\
S_{i}=\frac{1}{100} \sum_{k=1}^{\alpha_{i}} p_{i}^{k} x_{i}^{*_{k}} \quad \text { for } i=1,2, \ldots, n
\end{array}\right.
$$

where $S$ and $S_{i}$ are the average global and partial satisfaction indices, and $p^{m}$ and $p_{i}{ }^{k}$ are the frequencies of customers belonging to the $y^{m}$ and $x_{i}^{k}$ satisfaction levels, respectively.

It can be easily observed in equation (6) that the average satisfaction indices are basically the mean value of the global and partial satisfaction functions. So, these indices can give the average level of satisfaction value globally and per criterion.

\subsection{Demanding indices}

The shape of global and partial satisfaction functions can indicate customers' demanding level. The average global and partial demanding indices, $D$ and $D_{i}$ respectively, are assessed through the following equations (see Figure 3):

$$
\left\{\begin{array}{c}
D=\frac{\sum_{m=1}^{\alpha-1}\left(\frac{100(m-1)}{\alpha-1}-y^{*_{m}}\right)}{100 \sum_{m=1}^{\alpha-1} \frac{m-1}{\alpha-1}} \text { for } \alpha>2 \\
D_{i}=\frac{\sum_{k=1}^{\alpha_{i}-1}\left(\frac{100(k-1)}{\alpha_{i}-1}-x_{i}^{*_{k}}\right)}{100 \sum_{k=1}^{\alpha_{i}-1} \frac{k-1}{\alpha_{i}-1}} \text { for } \alpha_{i}>2 \text { and } i=1,2, \ldots, n
\end{array}\right.
$$

where $\alpha$ and $\alpha_{i}$ are the number of satisfaction levels in global and partial satisfaction functions, respectively.

It should be mentioned that these indices are normalised in the interval $[-1,1]$ while the following possible cases hold: 
a) $D=1$ or $D_{i}=1$ : customers have the highest demanding index.

b) $D=0$ or $D_{i}=0:$ this case refers to "neutral" customers.

c) $D=-1$ or $D_{i}=-1$ : customers have the lowest demanding index.

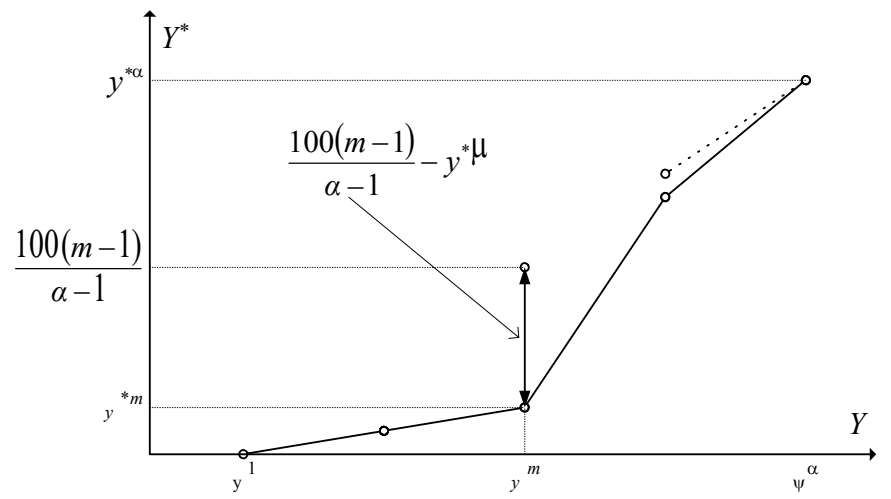

Figure 3. Calculating average demanding indices

These indices represent the average deviation of the estimated value functions from a "normal" (linear) function. The average demanding indices can be used for customer behaviour analysis, and they can also indicate the extent of company's improvement efforts: the higher the value of the demanding index, the more the satisfaction level should be improved in order to fulfil customers' expectations.

\subsection{Action diagrams}

Combining weights and average satisfaction indices, a series of action diagrams can be developed (Figure 4). These diagrams indicate the strong and the weak points of customer satisfaction, and define the required improvement efforts. Each of these maps is divided into quadrants, according to performance (high/low) and importance (high/low) that may be used to classify actions:

a) Status quo (low performance and low importance): Generally, no action is required.

b) Leverage opportunity (high performance/high importance): These areas can be used as advantage against competition.

c) Transfer resources (high performance/low importance): Company's resources may be better used elsewhere.

d) Action opportunity (low performance/high importance): These are the criteria that need attention. 


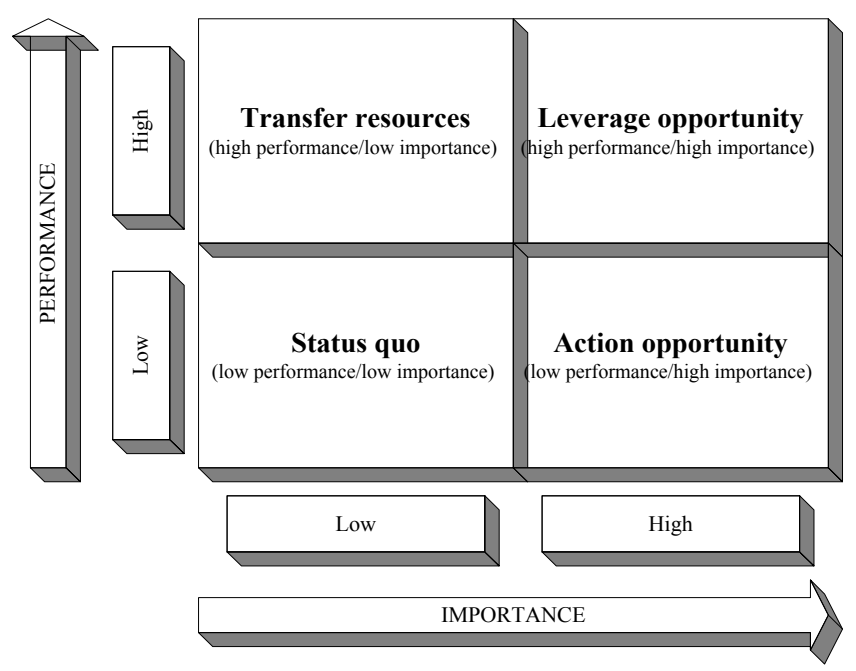

Figure 4. Action diagram (Customers Satisfaction Council, 1995)

In several cases, it is useful to assess the relative action diagrams, which use the relative variables $b_{i}^{\prime}$ and $S_{i}^{\prime}$ in order to overcome the assessment problem of the cut-off level for the importance and the performance axis. The normalised variables $b_{i}^{\prime}$ and $S_{i}^{\prime}$ are assessed as follows:

$$
b_{i}^{\prime}=\frac{b_{i}-\bar{b}}{\sqrt{\sum_{i}\left(b_{i}-\bar{b}\right)^{2}}} \text { and } S_{i}^{\prime}=\frac{S_{i}-\bar{S}}{\sqrt{\sum_{i}\left(S_{i}-\bar{S}\right)^{2}}} \text { for } i=1,2, \ldots, n
$$

where $\bar{b}$ and $\bar{S}$ are the mean values of the criteria weights and the average satisfaction indices, respectively.

This way, the cut-off level for axes is recalculated as the centroid of all points in the diagram. This type of diagram is very useful, if points are concentrated in a small area because of the low-variation that appears for the average satisfaction indices (e.g. case of a high competitive market)

These diagrams are also mentioned as decision, strategic, perceptual, and performance-importance maps (Dutka, 1995; Customers Satisfaction Council, 1995; Naumann and Giel, 1995), or gap analysis (Hill, 1996; Woodruff and Gardial, 1996; Vavra, 1997), and they are similar to SWOT analysis.

Detailed presentation of the mathematical development of the MUSA method may be found in Grigoroudis and Siskos (2001), and Siskos et al. (1998). 


\section{EVALUATING CUSTOMER SATISFACTION IN PUBLIC SERVICES}

\subsection{Application to a post office}

\subsubsection{Satisfaction criteria}

The assessment of a consistent family of criteria representing customers' satisfaction dimensions is one of most important stages of the implemented methodology. This assessment can be achieved through an extensive interactive procedure between the analyst and the decision-maker (company). In any case, the reliability of the set of criteria/subcriteria has to be tested in a small indicative set of customers.

The hierarchical structure of customers' satisfaction dimensions is presented in Figure 5 and indicates the set of criteria and subcriteria used in this survey. The main satisfaction criteria include:

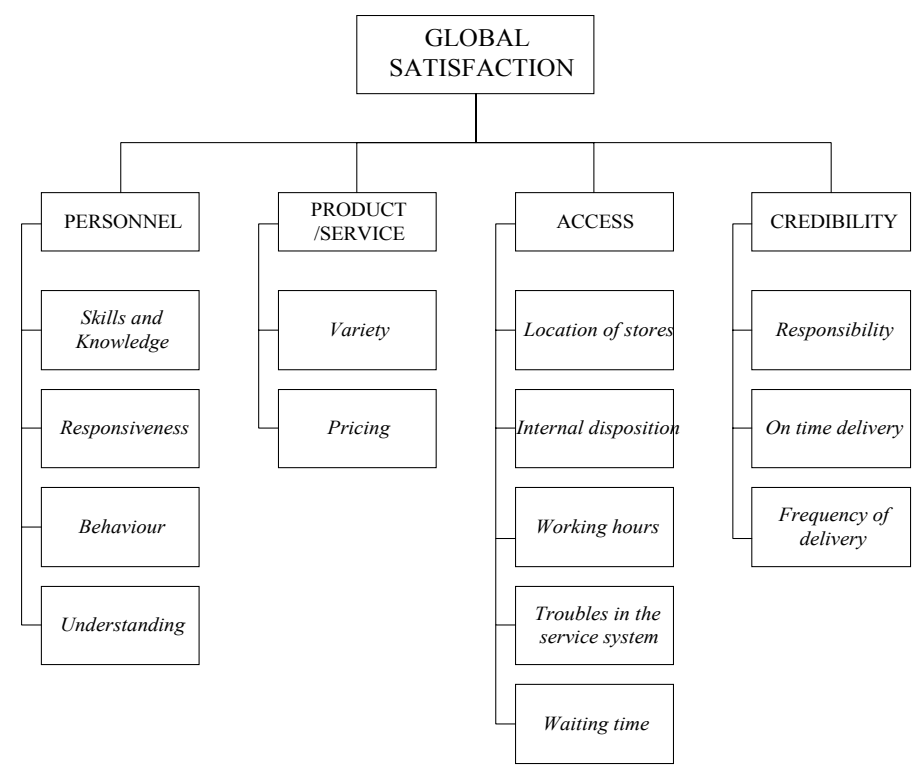

Figure 5. Hierarchical structure of satisfaction dimensions

- personnel (skills and knowledge, responsiveness, behaviour, etc),

- product/service (pricing, variety of provided services), 
- access (location and internal disposition of stores, working hours, waiting time, etc), and

- credibility (on time delivery, confidence and responsibility, etc).

\subsubsection{Global satisfaction analysis}

Company's customers seem to be quite satisfied with the provided service, given that the average global satisfaction index is almost $90 \%$. Moreover, criteria satisfaction analysis shows that customers are quite satisfied according to the total set of criteria (average satisfaction indices 8091\%). According to the results presented in Table 1 and Figure 2, the following remarks can be made:

Table 1. Global satisfaction results

\begin{tabular}{lrcc}
\hline Criteria & Weight & Average satisfaction index & Average demanding index \\
\hline Personnel & $5.48 \%$ & $91.07 \%$ & $-27.03 \%$ \\
Product/Service & $5.73 \%$ & $88.90 \%$ & $-30.19 \%$ \\
Access & $80.96 \%$ & $89.82 \%$ & $-90.12 \%$ \\
Credibility & $7.83 \%$ & $80.91 \%$ & $-48.88 \%$ \\
\hline Global satisfaction & & $89.20 \%$ & $-76.41 \%$ \\
\hline
\end{tabular}

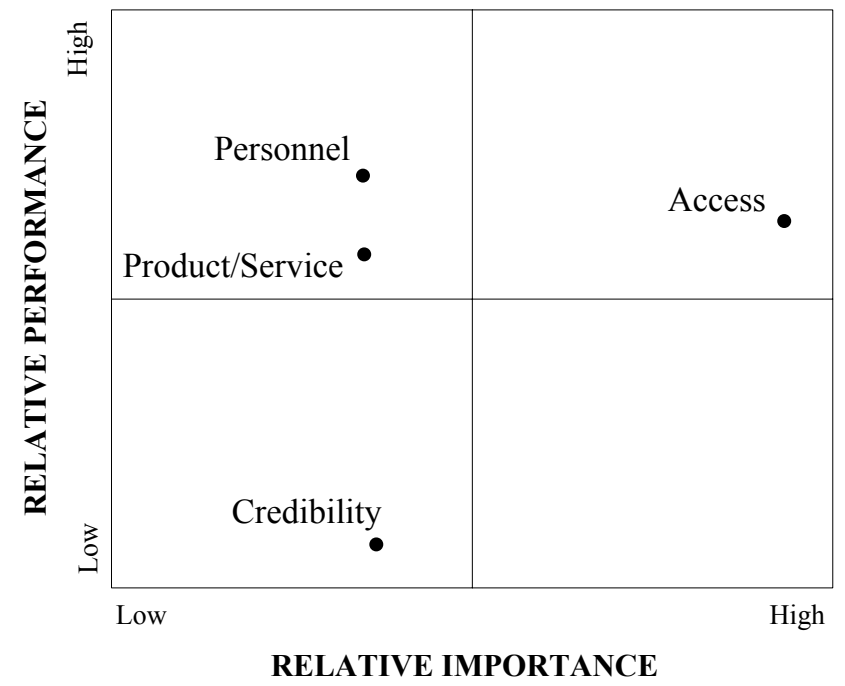

Figure 6. Relative Action diagram (global satisfaction level)

- The "Access" criterion is the most important one, with a significant weight of almost $81 \%$. This can be justified by the fact that the satisfaction survey was not conducted to the total clientele of the company, but it was oriented only to the customers visiting the stores. 
- Although the average satisfaction indices for all criteria are relatively high, it seems that there is a significant potential for further improvement, given the high competitive conditions in the market (new private companies offering express mail services).

- Customers do not seem to be demanding according to the total set of criteria.

- The action diagram shows that there are no critical satisfaction dimensions requiring immediate improvement efforts. However, if company wishes to create additional advantages against competition, the credibility criterion should be improved.

\subsubsection{Criteria satisfaction analysis}

The criteria satisfaction analysis confirms the conclusions of the previous section. In general, the company's performance is quite high in almost all satisfaction dimensions, which are considered important by the customers. This fact justifies the satisfactory level of the distinctive satisfaction indices. On the other hand, however, there are several areas where the company has significant margins for improvement.

The detailed results of Table 2 indicate the following points:

- Company's competitive advantages seem to be personnel's responsiveness and behaviour, variety and prices of provided products and services, waiting time and company's responsibility.

Table 2. Criteria satisfaction analysis

\begin{tabular}{lrrc}
\hline Subcriteria & Weight & $\begin{array}{c}\text { Average satisfaction } \\
\text { index }\end{array}$ & $\begin{array}{c}\text { Average demanding } \\
\text { index }\end{array}$ \\
\hline Skills/Knowledge & $8.5 \%$ & $74.6 \%$ & $-53.2 \%$ \\
Responsiveness & $26.0 \%$ & $92.5 \%$ & $-64.2 \%$ \\
Behaviour & $39.5 \%$ & $93.2 \%$ & $-21.3 \%$ \\
Understanding & $26.0 \%$ & $91.8 \%$ & $-69.2 \%$ \\
Variety & $50.0 \%$ & $86.2 \%$ & $-92.0 \%$ \\
Pricing & $50.0 \%$ & $91.6 \%$ & $-92.0 \%$ \\
Location of stores & $10.0 \%$ & $61.8 \%$ & $-20.0 \%$ \\
Internal disposition & $4.6 \%$ & $38.9 \%$ & $-13.3 \%$ \\
Working hours & $2.5 \%$ & $71.5 \%$ & $*$ \\
Service system troubles & $3.2 \%$ & $88.5 \%$ & $-89.9 \%$ \\
Waiting time & $79.7 \%$ & $96.9 \%$ & $-94.8 \%$ \\
Responsibility & $77.1 \%$ & $80.5 \%$ & $-71.5 \%$ \\
On time delivery & $14.1 \%$ & $89.4 \%$ & $-54.4 \%$ \\
Delivery frequency & $8.8 \%$ & $70.9 \%$ & \\
\hline
\end{tabular}

criteria with 2-level ordinal satisfaction scale 
- Although "Access" criterion is the most important strength of the post office, there are several aspects of this particular satisfaction dimension with large improvement margins (like working hours, location and internal disposition of stores). Customers seem less demanding in these subcriteria, and thus, improvement efforts may have an immediate impact.

\subsection{Application to a university department}

\subsubsection{Criteria assessment}

The case of measuring satisfaction in a university department can also be considered as an internal service quality evaluation process (Siskos et al., 2001). This application refers to a public and business administration department. Although it is focused on students' satisfaction, department's global evaluation should be oriented to all academic personnel (professors, administrative personnel, etc), as well as to external evaluators (business organisations, community, etc).

The main set of students' satisfaction criteria used in this particular survey consists of:

1. Academic personnel: this criterion refers to the educational skills and the knowledge of the academic personnel, their communication and collaboration with students, as well as the number of professors in the department.

2. Educational process: this criterion includes all aspects of the educational process like provided textbooks and notes, students evaluation process, educational approach chosen for each course, etc.

3. Syllabus: this criterion refers mainly to the number of the provided courses, the ability to adapt course of study to students' needs, etc.

4. Labour market: this criterion refers to the vocational rehabilitation of the graduated students (carrier services after graduation, adaptation of courses to labour market needs).

5. Administration: secretariat, academic advisor, administration service process, etc.

6. Additional services: this criterion includes the additional services that are provided to the students, like library, tutorial courses, subscription to journals and Internet services, audio-visual equipment, computer labs, etc.

Additional analysis has also been conducted, based on a detailed hierarchical structure of evaluation dimensions proposed by Siskos et al. (2001) for the case of a university department. 


\subsubsection{Global satisfaction analysis}

The average global satisfaction index is relatively low (61\%) mainly because students are not satisfied from the opportunities offered to the labour market $(26 \%)$, the syllabus $(26 \%)$, and the provided administrative service $(39 \%)$ as shown in Table 3.

Table 3. Criteria satisfaction results

\begin{tabular}{lcc}
\hline \multicolumn{1}{c}{ Criteria } & Weight & Average satisfaction index \\
\hline Academic personnel & $15 \%$ & $72 \%$ \\
Educational process & $29 \%$ & $83 \%$ \\
Syllabus & $15 \%$ & $26 \%$ \\
Labour market & $13 \%$ & $26 \%$ \\
Administration & $11 \%$ & $39 \%$ \\
Additional services & $17 \%$ & $77 \%$ \\
\hline Global satisfaction & & $61 \%$ \\
\hline
\end{tabular}

Additionally, the form of the global satisfaction function indicates that students are not particularly demanding (Figure 7). On the other hand, students seem to be quite satisfied according to the criterion of educational process $(83 \%)$, which is also the most important satisfaction dimension (weight 29\%). Finally, it should be noted that although the rest of the criteria have higher satisfaction indices (72-77\%) compared to the global satisfaction level, they appear to have significant improvement margins.

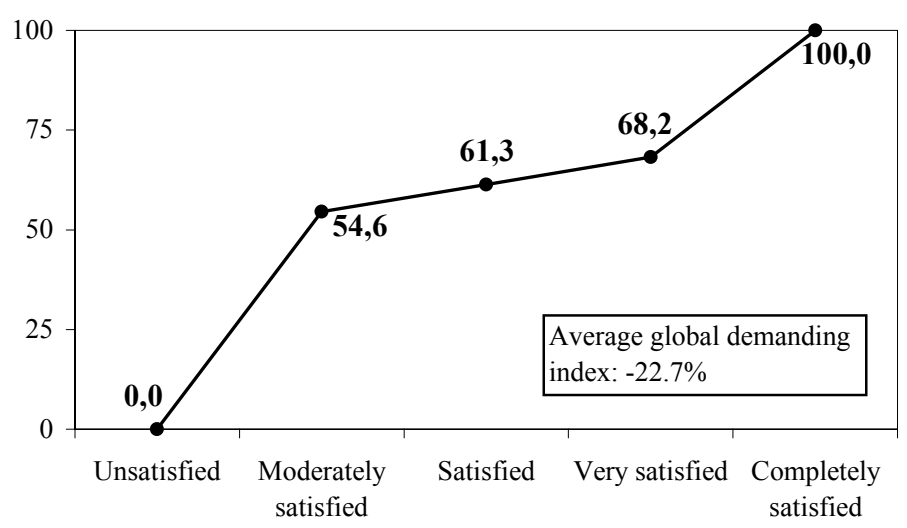

Figure 7. Global satisfaction function (added value curve) 


\subsubsection{Segmentation satisfaction analysis}

The main aim of this particular analysis is to determine students' clusters with distinctive preferences and expectations in relation to the total set. The discriminating variables that have been used for identifying special groups of students are the year of studies, the sector of studies, and the average grades.

The most important distinctive results relate to the segmentation according to the year of studies. The results of this analysis are presented in Tables 4-5, and reveal the following:

- Globally, $3^{\text {rd }}$ and $4^{\text {th }}$ year students are very dissatisfied from the university department. These students are the main reason for the low global satisfaction level.

- $1^{\text {st }}$ and $2^{\text {nd }}$ year students are less demanding, and thus, they have relatively higher average satisfaction index.

- The satisfaction level of the $1^{\text {st }}$ year students is higher compared to the other groups according to almost all of the criteria.

- The academic personnel, the syllabus, and the provided administrative and additional services have the lowest satisfaction level for $3^{\text {rd }}$ and $4^{\text {th }}$ year students. As students are closer to graduate, they seem to be more demanding at these particular satisfaction dimensions.

Table 4. Global satisfaction analysis per year of studies

\begin{tabular}{ccc}
\hline Year of studies & Average satisfaction index & Average demanding index \\
\hline $1^{\text {st }}$ & $78.6 \%$ & $-55.3 \%$ \\
$2^{\text {nd }}$ & $72.1 \%$ & $-44.8 \%$ \\
$3^{\text {rd }}$ & $24.5 \%$ & $50.3 \%$ \\
$4^{\text {th }}$ & $35.2 \%$ & $27.7 \%$ \\
\hline
\end{tabular}

\begin{tabular}{lcccc}
\multicolumn{5}{l}{ Table 5. Average partial satisfaction indices per year of studies } \\
\hline Criteria & $1^{\text {st }}$ year & $2^{\text {nd }}$ year & $3^{\text {rd }}$ year & $4^{\text {th }}$ year \\
\hline Academic personnel & $61 \%$ & $65 \%$ & $59 \%$ & $33 \%$ \\
Educational process & $67 \%$ & $64 \%$ & $29 \%$ & $72 \%$ \\
Syllabus & $62 \%$ & $91 \%$ & $31 \%$ & $18 \%$ \\
Labour market & $91 \%$ & $26 \%$ & $25 \%$ & $21 \%$ \\
Administration & $70 \%$ & $59 \%$ & $31 \%$ & $22 \%$ \\
Additional services & $73 \%$ & $66 \%$ & $13 \%$ & $40 \%$ \\
\hline
\end{tabular}

All these results can be explained by the way the course of studies is implemented:

a) During the $1^{\text {st }}$ year, students are basically taught elementary subjects (mathematics, sociology, etc).

b) At the beginning of the $3^{\text {rd }}$ year, students have to choose the sector of studies they will follow. This will affect in great extent all of their next choices. 
Segmentation satisfaction analysis is performed through the implementation of the MUSA method in each student's cluster separately. For this reason, the fitting and the stability level of the results may vary causing a problem of "inconsistency" when trying to compare global with segmentation analysis results. In this particular application, the problem mainly concerns the average satisfaction indices due to the high error level in the global satisfaction analysis (the global set is less homogenous than the segments of students).

\section{EVALUATING CUSTOMER SATISFACTION IN THE PRIVATE SECTOR}

\subsection{Application to a mobile phone service provider}

\subsubsection{Satisfaction criteria and survey conduct}

The implementation of the MUSA method includes a preliminary customer behavioural analysis in which, the assessment of the set of satisfaction criteria is made as presented in the previous applications.

In this particular case, customers were asked to evaluate/express their satisfaction according to the following criteria:

1. Stores (network expansion, location and appearance of stores, etc).

2. Service in stores (personnel, service processes, working hours, waiting time, etc).

3. Service by the call centre (personnel, service processes, waiting time, etc).

4. Products/Services (variety, mail phone, customer service, roaming, and additional info services)

5. Pricing (mobile phone device, fixed rate, prices per type of services, etc).

6. Image (technological excellence, credibility, ability to satisfy future needs, etc).

7. GSM network (expansion, signal, communication quality, and disturbances).

8. Customer loyalty services (phone device replacement, lower fixed rates, etc).

The presented customer satisfaction survey took place in two retail stores of the business organisation located in different areas. The survey was conducted within summer 2000 in a randomly selected customer sample. 


\subsubsection{Global satisfaction analysis}

The average global satisfaction index is not relatively high $(79.1 \%)$, given the high competitive conditions of the mobile phone service sector. Moreover, Table 6 shows that customers are quite satisfied according to the service provided in stores and to offered loyalty services, while lower satisfaction indices appear for the rest of the criteria (60\%-79\%). The most important criteria seem to be "Loyalty services" (24.9\%), "Service in store" (19.1\%), and "Products/Services" (11.4\%). This justifies the relative fair value of the global satisfaction index. Customers are more satisfied according to the most important criterion and less satisfied on the dimensions that seem to play a less important role to their preferences.

\begin{tabular}{lrcc}
\multicolumn{3}{l}{ Table 6. Global satisfaction results } \\
\hline Criteria & Weight & $\begin{array}{c}\text { Average satisfaction } \\
\text { index }\end{array}$ & $\begin{array}{c}\text { Average demanding } \\
\text { index }\end{array}$ \\
\hline Stores & $9.1 \%$ & $74.1 \%$ & $-12.3 \%$ \\
Service in store & $19.1 \%$ & $88.4 \%$ & $-58.0 \%$ \\
Service by the call centre & $8.2 \%$ & $60.6 \%$ & $-2.7 \%$ \\
Products/Services & $11.4 \%$ & $79.2 \%$ & $-29.6 \%$ \\
Pricing & $9.1 \%$ & $67.5 \%$ & $-12.3 \%$ \\
Image & $9.1 \%$ & $74.5 \%$ & $-12.3 \%$ \\
GSM network & $9.1 \%$ & $70.2 \%$ & $-12.3 \%$ \\
Customer loyalty services & $24.9 \%$ & $85.9 \%$ & $-67.8 \%$ \\
\hline Global satisfaction & & $79.1 \%$ & $-45.7 \%$ \\
\hline
\end{tabular}

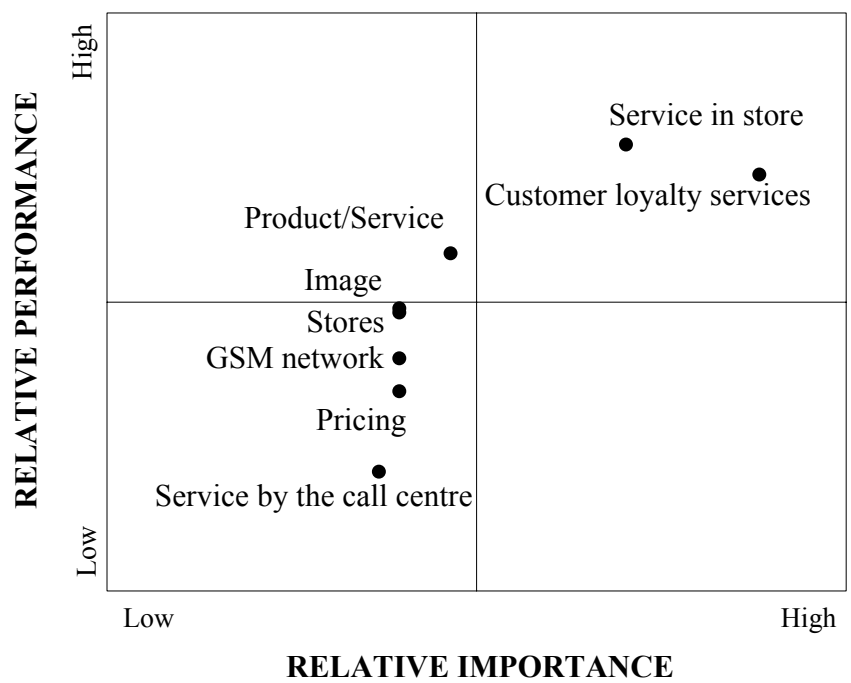

Figure 8. Relative action diagram 
The action diagram shows that there are no critical satisfaction dimensions requiring immediate improvement efforts, as presented in Figure 8. However, if company wishes to create additional advantages against competition, the criteria with the lowest satisfaction index should be improved. These improvement efforts should focus on service by the call centre, pricing, GSM network, stores, and company's image.

\subsubsection{Segmentation satisfaction analysis}

The most important results from customer satisfaction segmentation analysis are mainly focused on the discrimination of the total clientele to customers having or not having previous experience with other competitors. As shown in Table 7, experienced users are more satisfied according to almost all of the criteria set. The higher demanding level that appears in this particular customer group may confirm this result (Table 8).

Table 7. Average satisfaction indices per segment of customers

\begin{tabular}{lcc}
\hline Criteria & Experienced users & Inexperienced users \\
\hline Stores & $75.5 \%$ & $70.6 \%$ \\
Service in store & $84.7 \%$ & $73.8 \%$ \\
Service by the call centre & $63.0 \%$ & $54.6 \%$ \\
Products/Services & $75.0 \%$ & $72.8 \%$ \\
Pricing & $64.1 \%$ & $68.9 \%$ \\
Image & $89.5 \%$ & $73.2 \%$ \\
GSM network & $68.2 \%$ & $91.0 \%$ \\
Customer loyalty services & $70.4 \%$ & $75.8 \%$ \\
\hline Global satisfaction & $79.3 \%$ & $79.3 \%$ \\
\hline
\end{tabular}

\begin{tabular}{lcc} 
Table 8. Average demanding indices per segment of customers & \\
\hline Criteria & Experienced users & Inexperienced users \\
\hline Stores & $-14.2 \%$ & $-4.4 \%$ \\
Service in store & $-36.0 \%$ & $-4.42 \%$ \\
Service by the call centre & $-1.1 \%$ & $3.0 \%$ \\
Products/Services & $-14.2 \%$ & $-8.5 \%$ \\
Pricing & $-7.6 \%$ & $-8.5 \%$ \\
Image & $-25.5 \%$ & $-8.5 \%$ \\
GSM network & $-5.2 \%$ & $-77.9 \%$ \\
Customer loyalty services & $-14.2 \%$ & $-34.5 \%$ \\
\hline Global satisfaction & $-46.9 \%$ & $-42.5 \%$ \\
\hline
\end{tabular}

The detailed results of the previous segmentation analysis reveal the following: 
- When company's efforts are oriented to customers with previous experience from other mobile phone service providers, the advantages appearing in "Image" and "Service in stores" criteria should be used.

- On the other hand, the company should take advantage of the "GSM network" criterion, when its efforts are oriented to new customers with no experience in mobile phone services.

- In any case, company's improvement efforts should include "Pricing" and "Service by the call centre". These criteria appear relatively low satisfaction indices in both customer segments.

The variant level of homogeneity between the global set and the customer segments causes also in this case an "inconsistency" problem when trying to compare global with segmentation analysis results (see also §4.2.3). A detailed discussion on how to deal with possible implementation problems of the MUSA method (e.g. modifications of the LP formulation) is presented by Grigoroudis and Siskos (2001).

\subsection{The case of an airline company}

\subsubsection{Preliminary analysis}

The application presented in this section refers to a pilot customer satisfaction survey for an airline company. Passengers on board and customers visiting airline's agencies have both participated in this survey. The set of main satisfaction criteria consists of:

1. Tidiness (delays, booking system, timetable, etc).

2. Service (personnel, service time, waiting time, etc).

3. Pricing (ticket price and special discounts)

4. Credibility (safety of trip, baggage claim, damages, etc).

5. Comfort/Service quality (seats on board, quality of food, additional services, etc).

\subsubsection{Global satisfaction analysis}

The main results of the MUSA method are presented in Table 9, from where the following points raise:

- Globally, customers are quite satisfied from the provided service (global average satisfaction index $88.6 \%$ ).

- Nevertheless, based on the high competitive conditions of the market, there are significant improvement margins for several satisfaction dimensions. 
Multicriteria Analysis

Table 9. Global satisfaction results

\begin{tabular}{lrcc}
\hline Criteria & Weight & $\begin{array}{c}\text { Average satisfaction } \\
\text { index }\end{array}$ & $\begin{array}{c}\text { Average demanding } \\
\text { index }\end{array}$ \\
\hline Tidiness & $36.3 \%$ & $94.2 \%$ & $-89.0 \%$ \\
Service & $5.3 \%$ & $70.6 \%$ & $-22.8 \%$ \\
Pricing & $4.4 \%$ & $58.0 \%$ & $-9.0 \%$ \\
Credibility & $6.6 \%$ & $76.0 \%$ & $-34.3 \%$ \\
Comfort/Service quality & $47.3 \%$ & $90.1 \%$ & $-91.5 \%$ \\
\hline Global satisfaction & & $88.6 \%$ & $-51.1 \%$ \\
\hline
\end{tabular}

- The highest satisfaction indices appear for the criteria of "Tidiness" and "Comfort/Service quality", $94.2 \%$ and $90.1 \%$ respectively. Also, customers seem to give higher importance to these criteria.

- The rest of the criteria have a low level of importance for the customers (4.4-6.6\%), while the performance of the company is rather modest (average satisfaction indices 58-76\%).

Regarding the improvement efforts for the airline company, an inspection of the action diagram (Figure 9) reveals that there is no particularly critical satisfaction dimension calling for an immediate improvement. Nevertheless, the improvement priorities should be focused on the criteria with the lowest satisfaction indices. Assuming that the company has small improvement margins for the "Price" criterion due to the competition, its efforts should be focused on the credibility and the provided service.

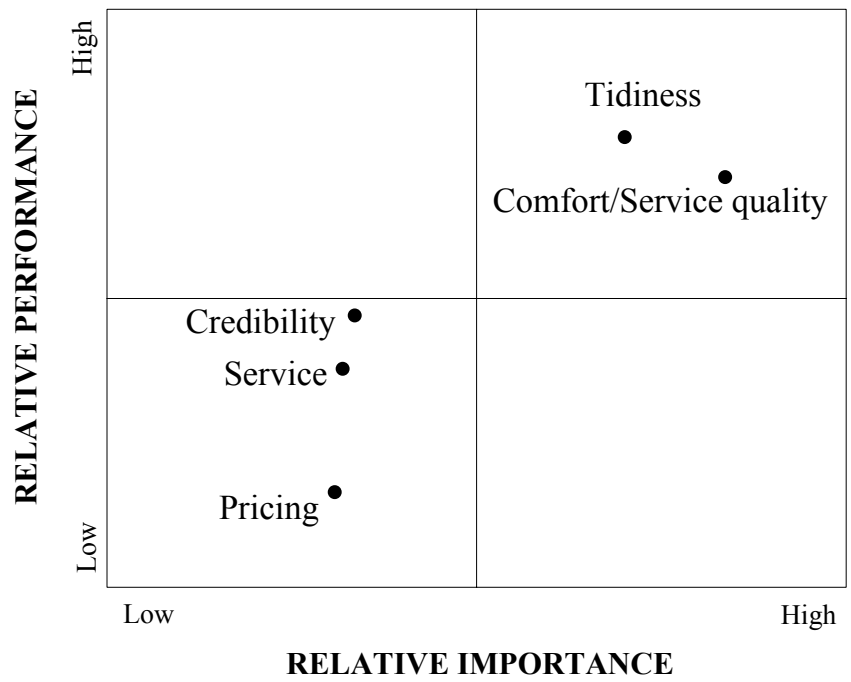

Figure 9. Relative action diagram 


\subsubsection{Segmentation satisfaction analysis}

The satisfaction analysis in different customer groups has been focused on the purpose of the trip. It should be noted that this particular customer satisfaction survey includes only international flights.

According to Tables 10-11, the comparative analysis of the customer clusters reveals the following:

- Passengers travelling for business give significant importance to the quality of the provided service, while they are not satisfied according to the company's pricing, service, and credibility. These customers can be also characterised as frequent users.

- On the other hand, passengers travelling for tourism give higher importance to company's credibility, while they are not satisfied according to criteria of "Pricing" and "Service". Usually these customers are not frequent users.

In any case, the lowest satisfaction indices appear for the company's prices, fact that justifies the main results presented in the previous section.

Table 10. Criteria weights per purpose of trip

\begin{tabular}{lcccc}
\hline Criteria & Business & Tourism & Personal & Other \\
\hline Tidiness & $20.0 \%$ & $19.2 \%$ & $51.5 \%$ & $35.8 \%$ \\
Service & $5.2 \%$ & $4.5 \%$ & $4.3 \%$ & $14.7 \%$ \\
Pricing & $4.4 \%$ & $4.2 \%$ & $4.2 \%$ & $9.5 \%$ \\
Credibility & $5.2 \%$ & $49.2 \%$ & $20.0 \%$ & $20.0 \%$ \\
Comfort/Service quality & $65.2 \%$ & $22.9 \%$ & $20.0 \%$ & $20.0 \%$ \\
\hline
\end{tabular}

\begin{tabular}{lcccc}
\multicolumn{5}{l}{ Table 11. Average satisfaction indices per purpose of trip } \\
\hline Criteria & Business & Tourism & Personal & Other \\
\hline Tidiness & $90.00 \%$ & $92.40 \%$ & $97.10 \%$ & $96.00 \%$ \\
Service & $71.90 \%$ & $65.70 \%$ & $60.90 \%$ & $93.00 \%$ \\
Pricing & $48.60 \%$ & $48.30 \%$ & $60.50 \%$ & $45.40 \%$ \\
Credibility & $67.40 \%$ & $97.20 \%$ & $83.10 \%$ & $82.00 \%$ \\
Comfort/Service quality & $94.30 \%$ & $90.50 \%$ & $89.40 \%$ & $91.00 \%$ \\
\hline Global satisfaction & $89.50 \%$ & $91.60 \%$ & $92.60 \%$ & $92.60 \%$ \\
\hline
\end{tabular}

\subsection{Application to a fast food company}

\subsubsection{Satisfaction criteria}

The presented customer satisfaction survey refers to a fast food company, which takes advantage of franchising options in order to hold more than 150 restaurants in four countries. The survey was conducted in a randomly 
selected customer sample and it took place in three restaurants of the fast food company located in different towns.

The value hierarchy of customers satisfaction dimensions presented in Figure 10 indicates the set of criteria and subcriteria used in the analysis. The main satisfaction criteria include:

1. Personnel: this criterion includes all the characteristics concerning personnel (skills and knowledge, responsiveness, friendliness, communication and collaboration with customers, etc).

2. Product: this criterion refers mainly to the offered products (quality and quantity of food, variety of dishes, and prices).

3. Service: this criterion refers to the service offered to the customers; it includes the appearance and the cleanliness of the stores, the waiting time during busy and non-busy hours, and the service time.

4. Access: the location and number of stores, as well as parking availability are included in this criterion.

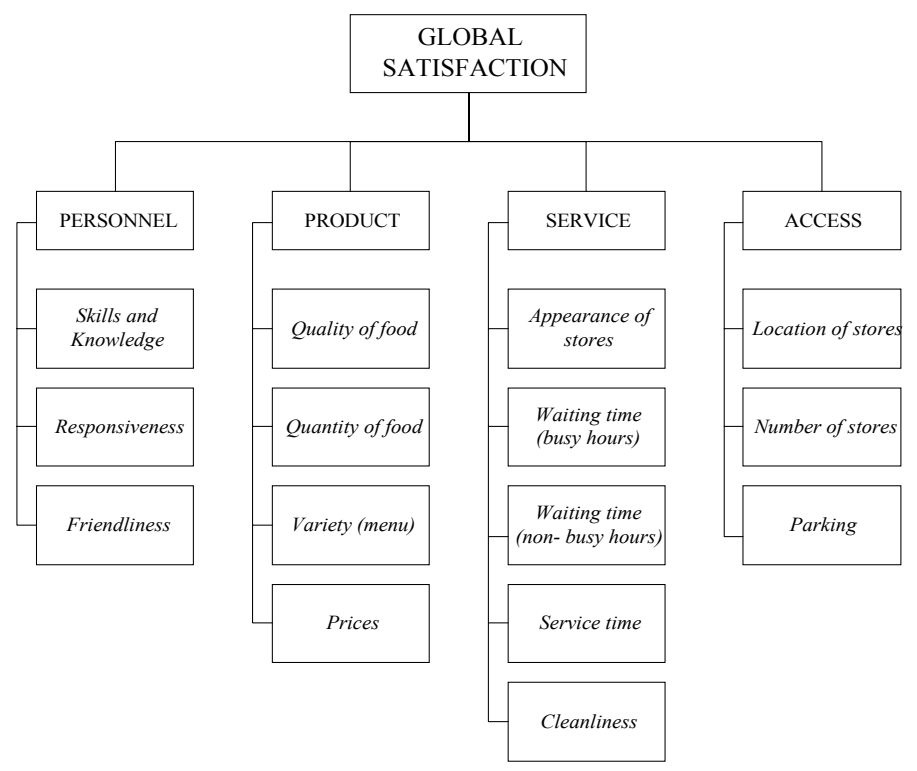

Figure 10. Hierarchical structure of satisfaction dimensions

\subsubsection{Global satisfaction analysis}

The average global satisfaction index is approximately $90 \%$, while company's performance according to the whole set of criteria varies between 
$86 \%$ and $92 \%$. Given the high competitive conditions of the market, this performance is not considered relatively high.

The detailed results of Table 12 reveal the following:

- The most important criterion, with a significant importance level of $45.2 \%$, is "Product". Customers do not consider important the rest of the criteria.

- The low weight for the "Access" criterion can be explained by the fact that the main competitors have no better performance in this particular criterion.

Table 12. Global satisfaction results

\begin{tabular}{lccc}
\hline Criteria & Weight & Average satisfaction index & Average demanding index \\
\hline Personnel & $22.00 \%$ & $92.44 \%$ & $-75.20 \%$ \\
Product & $45.20 \%$ & $86.56 \%$ & $-68.61 \%$ \\
Service & $25.00 \%$ & $88.08 \%$ & $-66.21 \%$ \\
Access & $10.70 \%$ & $87.19 \%$ & $-85.01 \%$ \\
\hline Global satisfaction & & $90.81 \%$ & $-73.20 \%$ \\
\hline
\end{tabular}

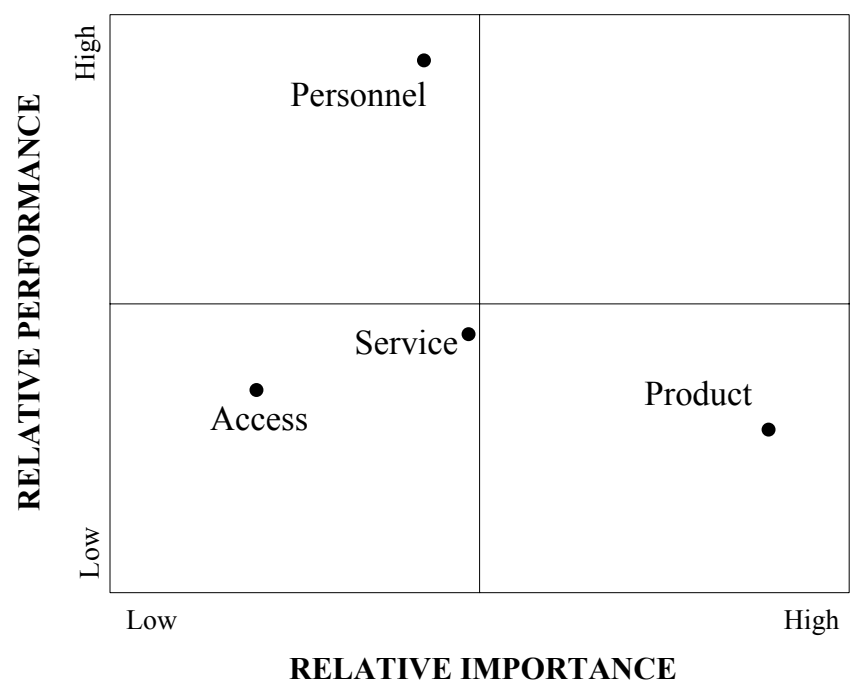

Figure 11. Relative action diagram (global satisfaction level)

Combining weights and satisfaction indices, the action diagram can be formulated, as shown in Figure 11. In this diagram, the "Product" criterion appears as a critical satisfaction dimension requiring immediate improvement efforts: it has the lowest average satisfaction index comparing to the rest of the criteria, while it is considered as the most important criterion by customers. 


\subsubsection{Criteria satisfaction analysis}

The analysis of the partial satisfaction dimensions allows for the identification of the criteria characteristics that constitute the strong and the weak points of the company. The detailed results of Table 13, reveal the following:

- Personnel's friendliness constitutes a significant competitive advantage for the fast food company.

- The quality of food appears as one of the strongest points of the company, although customers do not seem to be satisfied according to the quantity of food. This result is related to the low satisfaction index appearing for the "Price" criterion.

- Particular attention should be paid to the waiting time during busy hours and the service time as well. On the other hand, the appearance of the restaurants seems to be one of the competitive advantages for the fast food company.

- The satisfaction level with respect to the "Access" criterion could have been higher, if customers were more satisfied according to the provided parking facilities.

Table 13. Criteria satisfaction results

\begin{tabular}{|c|c|c|c|}
\hline Subcriteria & Weight & $\begin{array}{c}\text { Average satisfaction } \\
\text { index }\end{array}$ & $\begin{array}{c}\text { Average demanding } \\
\text { index }\end{array}$ \\
\hline Skills/Knowledge & $34.0 \%$ & $93.10 \%$ & $-71.3 \%$ \\
\hline Responsiveness & $15.9 \%$ & $83.60 \%$ & $-62.1 \%$ \\
\hline Friendliness & $50.1 \%$ & $94.80 \%$ & $-82.0 \%$ \\
\hline Quality of food & $49.8 \%$ & $90.40 \%$ & $-84.4 \%$ \\
\hline Quantity of food & $13.3 \%$ & $77.30 \%$ & $-40.9 \%$ \\
\hline Variety (menu) & $25.0 \%$ & $90.90 \%$ & $-68.5 \%$ \\
\hline Prices & $11.9 \%$ & $71.70 \%$ & $-33.7 \%$ \\
\hline Appearance of stores & $42.8 \%$ & $90.80 \%$ & $-81.0 \%$ \\
\hline Waiting time (busy hours) & $8.5 \%$ & $68.60 \%$ & $-29.8 \%$ \\
\hline Waiting time (non-busy hours) & $19.2 \%$ & $90.90 \%$ & $-69.4 \%$ \\
\hline Service time & $8.3 \%$ & $74.10 \%$ & $-28.8 \%$ \\
\hline Cleanliness & $21.2 \%$ & $93.30 \%$ & $-62.7 \%$ \\
\hline Location of stores & $87.1 \%$ & $90.70 \%$ & $-93.4 \%$ \\
\hline Number of stores & $6.8 \%$ & $81.10 \%$ & $-42.3 \%$ \\
\hline Parking & $6.1 \%$ & $43.90 \%$ & $-12.9 \%$ \\
\hline
\end{tabular}

\section{CONCLUSIONS}

The original applications presented in this paper illustrate the implementation of the preference disaggregation MUSA method in several 
business organisations from the public and the private sector. The most important results include:

- the determination of the weak and the strong points of the business organisation,

- the performance evaluation of the company (globally and per criteria/subcriteria), and

- the identification of the distinctive critical groups of customers.

The applications show that the MUSA method can measure and analyse customer satisfaction in a very concrete way, and thus it may be integrated in any business organisation's total quality approach. Several applications of the method in original customer satisfaction surveys can be found in Grigoroudis et al. (1999a, 1999b), Mihelis et al. (2001), and Siskos et al. (2001). Also, the MUSA method may be used in a similar way to measure and analyse employee satisfaction (Grigoroudis, 1999). Furthermore, analysing clients' preferences and expectations is the basic step to evaluate customer loyalty.

The installation of a permanent customer satisfaction barometer is considered necessary, given that it allows the establishment of a benchmarking system (Edosomwan, 1993). Thus, the implementation of the MUSA method through a period of time can serve the concept of continuous improvement.

Grigoroudis and Siskos (2001) propose several extensions and future research regarding the MUSA method. Among others, the comparative analysis between the results of the MUSA method and the financial indices (market share, profit, etc) of a business organisation can help the development of business strategies and the evaluation of the cost of quality. It should be mentioned that, although customer satisfaction is a necessary but not a sufficient condition for the financial viability, several researches have shown that there is a significant correlation among satisfaction level, customer loyalty, and profitability (Dutka, 1995; Naumann and Giel, 1995).

\section{ACKNOWLEDGEMENTS}

The authors are thankful to all the students of the National Technical University of Athens and the University of Cyprus who helped customer satisfaction survey conduct and analysis. Especially, the authors would like to thank: P. Apseros, N. Eteokleous, T. Georgiou, L. Giannoudiou, A. Grigoriou, E. Karekla, M. Konstantinidou, K. Kotsonis, L. Morfitou, A. Mousa, D. Nikolaou, L. Panagidou, E. Papadopoulou, Y. Papathanasiou, M. Pimpisii, E. Pissaridi, M. Spirou, G. Stathopoulos, A. Tamani, and D. Venezis. 


\section{REFERENCES}

Customers Satisfaction Council (1995). Customer Satisfaction Assessment Guide, Motorola University Press.

Dutka A. (1995). AMA Handbook of customer satisfaction: A complete guide to research, planning and implementation, NTC Business Books, Illinois

Edosomwan J. A. (1993). Customer and market-driven quality management, ASQC Quality Press, Milwaukee.

Gerson R. F. (1993). Measuring customer satisfaction: A guide to managing quality service, Crisp Publications, Menlo Park.

Grigoroudis E. (1999). Measuring and analysing satisfaction methodology: A multicriteria aggregation-disaggregation approach, Ph.D. Thesis, Technical University of Crete, Department of Production Engineering and Management, Chania (in greek).

Grigoroudis E. and Y. Siskos (2001). Preference disaggregation for measuring and analysing customer satisfaction: The MUSA method, European Journal of Operational Research (to appear).

Grigoroudis E., A. Samaras, N. F. Matsatsinis and Y. Siskos (1999a). Preference and customer satisfaction analysis: An integrated multicriteria decision aid approach, Proceedings of the 5th Decision Sciences Institute's International Conference on Integrating Technology \& Human Decisions: Global Bridges into the 21st Century, Athens, Greece, (2), 1350-1352.

Grigoroudis E., J. Malandrakis, J. Politis and Y. Siskos (1999b). Customer satisfaction measurement: An application to the Greek shipping sector, Proceedings of the 5th Decision Sciences Institute's International Conference on Integrating Technology \& Human Decisions: Global Bridges into the 21st Century, Athens, Greece, (2), 1363-1365.

Hill, N. (1996). Handbook of customer satisfaction measurement, Gower Publishing, Hampshire.

Jacquet-Lagrèze E. and J. Siskos (1982). Assessing a set of additive utility functions for multicriteria decision-making: The UTA method, European Journal of Operational Research, (10), 2, 151-164.

Keeney R. L. (1996). Value-focused thinking: A path to creative decisionmaking, Harvard University Press.

Keeney R. L. and H. Raiffa (1976). Decisions with multiple objectives: Preferences and value tradeoffs, John Wiley and Sons, New York.

Kirkwood G. W. (1997). Strategic decision making, Duxbury Press, Belmont.

Mihelis G., E. Grigoroudis, Y. Siskos, Y. Politis and Y. Malandrakis (2001). Customer satisfaction measurement in the private bank sector, European Journal of Operational Research, (130), 2, 347-360.

Naumann E. and K. Giel (1995). Customer satisfaction measurement and management: Using the voice of the customer, Thomson Executive Press, Cincinnati.

Siskos J. (1985). Analyse de regression et programmation linéaire, Revue de Statistique Appliquée, 23 (2), 41-55.

Siskos J. and D. Yannacopoulos (1985). UTASTAR: An ordinal regression method for building additive value functions, Investigaçao Operacional, 5 (1), 39-53.

Siskos Y., E. Grigoroudis, C. Zopounidis and O. Saurais (1998). Measuring customer satisfaction using a collective preference disaggregation model, Journal of Global Optimization, 12, 175-195. 
Siskos Y., Y. Politis and G. Kazantzi (2001). Multicriteria methodology for the evaluation of higher education systems: The case of an engineering department, HELORS Journal (to appear).

Vavra T. G. (1997). Improving your measurement of customer satisfaction: A guide to creating, conducting, analyzing, and reporting customer satisfaction measurement programs, ASQC Quality Press, Milwaukee.

Woodruff R. B. and S. F. Gardial (1996). Know your customer: New approaches to understanding customer value and satisfaction, Blackwell Publishers, Oxford. 